\title{
TITLE:
}

\section{Fabrication of (101)-oriented CsPbBr thick films with high carrier mobility using a mist deposition method}

AUTHOR(S):

Haruta, Yuki; Ikenoue, Takumi; Miyake, Masao; Hirato, Tetsuji

\section{CITATION:}

Haruta, Yuki ... [et al]. Fabrication of (101)-oriented CsPbBr thick films with high carrier mobility using a mist deposition method. Applied Physics Express 2019, 12(8): 085505.

ISSUE DATE:

2019-08-01

URL:

http://hdl.handle.net/2433/252471

\section{RIGHT:}

This is an author-created, un-copyedited version of an article accepted for publication/published in Applied Physics Express. IOP Publishing Ltd is not responsible for any errors or omissions in this version of the manuscript or any version derived from it. The Version of Record is available online at https://doi.org/10.7567/1882-0786/ab2c96.; この論文は出版 社版でありません。引用の際には出版社版をご確認ご利用ください。; This is not the published version. Please cite only the published version. 


\title{
Fabrication of (101)-oriented $\mathrm{CsPbBr}_{3}$ thick films with high carrier mobility using a mist deposition method
}

\author{
Yuki Haruta $^{1}$, Takumi Ikenoue ${ }^{1 *}$, Masao Miyake ${ }^{1}$, and Tetsuji Hirato ${ }^{1}$ \\ ${ }^{1}$ Graduate School of Energy Science, Kyoto University, Kyoto, 606-8501, Japan \\ E-mail: ikenoue.takumi.4m@kyoto-u.ac.jp
}

$\mathrm{CsPbr}_{3}$ is a promising candidate for highly sensitive flat-panel $\mathrm{X}$-ray detectors due to its excellent optoelectronic properties. Thus, a method of preparing thick $\mathrm{CsPbBr}_{3}$ films $(>10$ $\mu \mathrm{m})$ over large areas $\left(>10 \times 10 \mathrm{~cm}^{2}\right)$ is required. Herein, we report the fabrication of thick $\mathrm{CsPbBr} 3$ films using a scalable mist deposition method. In this method, the film thickness was controlled and up-scaled by the number of deposition cycles. The obtained $\mathrm{CsPbBr}_{3}$ films were composed of highly (101)-oriented columnar crystals and had a high carrier mobility of $13 \mathrm{~cm}^{2} \mathrm{~V}^{-1} \mathrm{~s}^{-1}$, which is comparable to that for single crystals.

A highly sensitive flat-panel X-ray detector (FPD), which enables medical X-ray imaging at low dose, is required to reduce the risk of cancer ${ }^{1}$. Amorphous selenium (a-Se) is commonly used for the photoconductive layer because it can be prepared through simple methods such as thermal evaporation. However, the sensitivity of FPD using a-Se is limited due to its low mobility-lifetime $(\mu \tau)$ product of $10^{-6} \mathrm{~cm}^{2} \mathrm{~V}^{-12,3)}$. Solution-processed lead halide perovskite materials ${ }^{4-7)}\left(\mathrm{CH}_{3} \mathrm{NH}_{3} \mathrm{PbI}_{3}, \mathrm{CH}_{3} \mathrm{NH}_{3} \mathrm{PbBr}_{3}, \mathrm{CsPbBr}_{3}\right.$, etc. $)$ are promising candidates for the photoconductive layer of highly-sensitive FPDs due to their excellent optoelectronic properties including a high attenuation coefficient and exceptional carrier transport properties ${ }^{8-11)}$. C. C. Stoumpos et al. prepared melt-grown $\mathrm{Cs} \mathrm{PbBr}_{3}$ single crystals (SCs) with high $\mu \tau$ product of $\sim 10^{-3} \mathrm{~cm}^{2} \mathrm{~V}^{-1}$ by using the Bridgman method and demonstrated that $\mathrm{CsPBr}_{3}$ is a promising candidate material for $\mathrm{X}$ - and $\gamma$-ray detection ${ }^{12)}$. In addition, D. N. Dirin et al. succeeded the preparation of solution-grown $\mathrm{CsPbBr}_{3} \mathrm{SCs}$ by using the inverse temperature crystallization method (ITC) and reported its $\mu \tau$ product of $\sim 10^{-4} \mathrm{~cm}^{2} \mathrm{~V}^{-1}$ which is slightly lower than that of melt-grown $\mathrm{CsPbBr}_{3} \mathrm{SCs}$ but higher than that of a-Se ${ }^{13)}$. However, it is not feasible to prepare $\mathrm{CsPbBr}_{3}$ SCs having large-area $\left(>10 \times 10 \mathrm{~cm}^{2}\right)$, which is required for FPD applications. Even CdTe SCs have not been applied to large-area FPD yet, although they have been already commercialized to X-ray detectors ${ }^{14)}$. Hence, 
polycrystalline films are considered as realistic choices for the photoconductive layer of FPD due to their potentials for large-scale fabrication. Recently, Zhi Yang et al. reported the preparation of $\mathrm{CsPbBr}_{3}$ quantum dot film of $10 \times 10 \mathrm{~cm}^{2}$ for large-scale application of perovskite optoelectronics, but its thickness $(<800 \mathrm{~nm})$ is not enough to absorb X-ray photons ${ }^{15}$. Over and above that, spin coating ${ }^{7,16-19)}$, layer-by-layer deposition ${ }^{20)}$, and other methods ${ }^{21-23)}$ have been proposed to prepare polycrystalline $\mathrm{CsPbBr}_{3}$ films. However, none of these methods are applicable to the preparation of thick $\mathrm{CsPbBr}_{3}$ films $(>10 \mu \mathrm{m})$. Besides, the carrier transport properties of $\mathrm{CsPbBr}_{3}$ polycrystalline films are often poor than that of SCs, resulting in poor device performances ${ }^{24,25)}$. Therefore, a scalable method for the preparation of thick $\mathrm{CsPbr}_{3}$ films with high carrier transport properties is required to achieve FPD application. A mist deposition method is a good candidate due to its track records of large-area film fabrication ${ }^{26-33)}$ and hybrid perovskites film fabrication ${ }^{34)}$. In addition, this method seems to have potentials for the increase of film thickness by repeating fabrication process because a precursor solution is atomized and the mist is injected to the pre-heated underlying film, resulting in fast solvent-evaporation and the growth of the film without remarkable dissolution damages.

In this work, we report the fabrication of thick $\mathrm{CsPbBr}_{3}$ films (>20 $\left.\mu \mathrm{m}\right)$ using the mist deposition method. The effect of the substrate temperature was studied and it was revealed that films formed at $150-170{ }^{\circ} \mathrm{C}$ were closely packed with (101)-oriented orthorhombic $\mathrm{CsPbBr}$. In addition, the film thickness was controlled and up-scaled by the number of deposition cycles. The obtained $\mathrm{CsPbBr}_{3}$ films were composed of highly (101)-oriented columnar crystals and had high carrier transport properties, which are comparable to that for CsPbBr 3 SCs.

$\mathrm{CsPbBr}_{3}$ films were prepared using a mist deposition method (Figure 1). A precursor solution, which was prepared by dissolving $50 \mathrm{mM}$ CsBr (Sigma-Aldrich, 99.999\%) and 50 $\mathrm{mM} \mathrm{PbBr} 2$ (Sigma-Aldrich, 99.999\%) in a solvent mixture of DMSO (Wako, 99.0\%) and DMF (Wako, 99.5\%) (1:1, volume ratio), was atomized by $2.4 \mathrm{MHz}$ ultrasonic vibration. This mist was then transported by nitrogen gas and injected from a nozzle with a rectangular aperture $\left(30 \times 1 \mathrm{~mm}^{2}\right)$ to the pre-heated glass substrate $\left(130-190{ }^{\circ} \mathrm{C}\right)$ as a curtain-like flow. The carrier gas flow rate and dilution gas flow rate were set at 0.4 and $4.6 \mathrm{~L} \mathrm{~min}{ }^{-1}$, respectively. $\mathrm{CsPbBr}$ can be uniformly deposited over a wide area by passing the substrate under the mist flow at a constant speed. In this study, $\mathrm{CsPbBr} 3$ was deposited onto a reduced area of $25 \times 6 \mathrm{~mm}^{2}$ by moving the substrate by $6 \mathrm{~mm}$ at a speed of $0.16 \mathrm{~mm} \mathrm{~s}^{-1}$. The deposition cycle was repeated to give a thick $\mathrm{CsPbBr}_{3}$ film. X-ray diffraction (XRD) spectra 
of $\mathrm{CsPbBr}_{3}$ films were recorded using a PW 3040/60 X'Pert PRO with Cu-Ka radiation. Cross-sections of the films were observed with scanning electron microscopy (SEM; JSM6510LV, JEOL). To investigate the carrier transport properties, a $\mathrm{Pt} / \mathrm{CsPbBr}_{3} /$ carbon structure was fabricated as follows: a Pt thin film as an ohmic electrode was formed on an ITO/glass substrate $\left(25 \times 20 \mathrm{~mm}^{2}\right)$ by sputtering deposition. The $\mathrm{CsPBBr}_{3}$ film was deposited onto the Pt film at $150^{\circ} \mathrm{C}$ in the same way as the fabrication on glass substrates. Finally, a circular carbon ohmic electrode was deposited onto the $\mathrm{CsPbBr} 3$ film by painting carbon ink and heating at $100{ }^{\circ} \mathrm{C}$ for $10 \mathrm{~min}$. This process was chosen to prevent the $\mathrm{CsPbBr}_{3}$ film from being damaged by heat or incident particles with a high energy. The active area was measured to be $0.07 \mathrm{~cm}^{2}$. The dark current density-voltage curve was measured with a Keithley 2400 Source Meter. In this measurement, carbon and Pt electrodes served as the anode and cathode, respectively.

Figures 2(a)-(d) shows photographs of $\mathrm{CsPbBr}_{3}$ films formed on glass substrates at various substrate temperatures $\left(130-190^{\circ} \mathrm{C}\right)$ to examine the temperature-dependence. Clear orange-colored films were obtained at $150-170{ }^{\circ} \mathrm{C}$, while frosted films were obtained at 130 and $190^{\circ} \mathrm{C}$. The cross-sectional SEM images (Figs. 2(e)-(h)) showed that the films formed at $150-170{ }^{\circ} \mathrm{C}$ were composed of closely packed columnar crystals with diameters of 1-2 $\mu \mathrm{m}$, whereas those at lower and higher temperatures (130 and $190{ }^{\circ} \mathrm{C}$ ) were composed of rough grains, corresponding to clear or frosted appearances (Figs. 2(a)-(d)). When the substrate temperature was set at $150-170{ }^{\circ} \mathrm{C}$, the supply of precursor solution and solvent evaporation seemed to be well-balanced, resulting in the formation of high-quality films. The XRD patterns of the films corresponded to that of orthorhombic $\mathrm{CsPbBr}_{3}{ }^{12)}$ (Fig. 2(i)). It is known that $\mathrm{CsPbBr}_{3}$ exists in an orthorhombic structure at room temperature, with phase transitions to tetragonal and cubic structures at $88^{\circ} \mathrm{C}$ and $130{ }^{\circ} \mathrm{C}$, respectively ${ }^{12)}$. The films can be identified as an orthorhombic structure due to the specific peaks, such as (201) at $2 \theta$ $=24.2^{\circ}$. The bandgap of the film derived from the visible absorption spectrum (Fig. 2(j)) was $2.33 \mathrm{eV}$, in agreement with the value reported for $\mathrm{CsPbBr}_{3}{ }^{7,35,36)}$. These results showed that $\mathrm{CsPbBr}_{3}$ films were indeed obtained using the mist deposition method. Interestingly, the films formed at $150-170^{\circ} \mathrm{C}$ were composed of highly (101)-oriented columnar crystals (Figs. 2(f), 2(g), and 2(i)). Columnar growth should be preferable because it creates few grain boundaries that cross the charge collection route, thus $150{ }^{\circ} \mathrm{C}$ was selected as the substrate temperature in the following sections.

The number of deposition cycles $(N)$ was increased to fabricate thick $\mathrm{CsPbBr}_{3}$ films. The film thickness increased in proportion to the number of deposition cycles (Figure 3(a)), 
showing that the film thickness was controlled effectively in this method. In addition, columnar crystals continued growing while maintaining their structure (Figs. 3(b)-(d)).

The carrier transport properties of the $\mathrm{CsPbBr}_{3}$ film in the direction vertical to the substrates were determined through space-charge limited current (SCLC) measurements ${ }^{37)}$ with an ohmic device ( $\mathrm{Pt} / \mathrm{CsPbBr}_{3} /$ Carbon). In the current density-voltage $\left(J \approx V^{n}\right)$ curve, ohmic ( $n=1)$, trap-filling (TFL, $n>3$ ), and Child $(n=2)$ regions were observed (Figure 4 ). The resistivity $(R)$ was calculated from the ohmic region and the trap density $\left(n_{\text {trap }}\right)$ was calculated using the equation:

$$
n_{\text {trap }}=\frac{2 V_{\mathrm{TFL}} \varepsilon \varepsilon_{0}}{e L^{2}}
$$

where $V_{\mathrm{TFL}}$ is the trap-filled limit voltage, $L$ is the film thickness of $27.7 \mu \mathrm{m}$ (measured from cross-sectional SEM image of this sample), $\varepsilon_{0}$ is the vacuum permittivity, $e$ is the electron charge, and $\varepsilon$ is the relative dielectric constant for $\operatorname{CsPbBr}_{3}\left(\sim 23.9^{35}\right)$. The mobility $(\mu)$ was calculated from the Child region following Mott-Gurney’s equation:

$$
\mu=\frac{8 J_{D} L^{3}}{9 \varepsilon \varepsilon_{0} V^{2}}
$$

where $J_{\mathrm{D}}$ is the current density. The results of the SCLC measurements are summarized in Table I with previous reports. The resistivity $(R)$ is $1.4 \mathrm{G} \Omega \mathrm{cm}$, which is comparable to that for solution-grown $\mathrm{CsPbBr}_{3} \mathrm{SCs}^{38,39)}$ and expected to contribute to the suppression of noise current. The trap-filled limit voltage $\left(V_{\mathrm{TFL}}\right)$ is $0.37 \mathrm{~V}$ for this sample and the trap density ( $n_{\text {trap }}$ ) calculated from Equation (1) is $1.3 \times 10^{12} \mathrm{~cm}^{-3}$, which is relatively higher than that for $\mathrm{CsPbr}_{3}$ SCs but lower than that for polycrystalline films ${ }^{40,41)}$. In addition, the mobility $(\mu)$ calculated from Equation (2) is $13 \mathrm{~cm}^{2} \mathrm{~V}^{-1} \mathrm{~s}^{-1}$, which is comparable to that for $\mathrm{CsPbBr}_{3} \mathrm{SCs}$ ${ }^{35,38)}$ and higher than that for high-quality $\mathrm{CsPbBr}_{3}$ thin films ${ }^{40)}$. Generally, the mobility of polycrystalline films is lower than that for single crystals due to the grain boundaries. In the case of $\mathrm{CH}_{3} \mathrm{NH}_{3} \mathrm{PbI}_{2} \mathrm{Cl}$ polycrystalline films, the dramatical deterioration of the mobility with increasing grain boundaries has been reported ${ }^{42}$. However, the $\mathrm{CsPbBr}_{3}$ films fabricated by the mist deposition method had high carrier mobility. We speculate that reason as follows. As shown in the inset of Fig. 4, in the (101)-oriented $\mathrm{CsPbBr}_{3}$ films, the $\left[\mathrm{PbBr}_{6}\right]^{4-}$ octahedrons align in the direction of charge collection and the $\mathrm{Br}-\mathrm{Pb}-\mathrm{Br}$ continuous bonds form straight chains, leading to effective carrier transport ${ }^{35}$ ). In addition, the columnar growth created few grain boundaries to disturb carrier transport. Both (101)-orientation and columnar growth seemed to contribute to the high carrier mobility.

In conclusion, a mist deposition method was successfully applied for the fabrication of thick $\mathrm{CsPbBr}_{3}$ films. Highly (101)-oriented $\mathrm{CsPbBr}_{3}$ films composed of columnar crystals 
were obtained in a temperature range of $150-170{ }^{\circ} \mathrm{C}$. Furthermore, the film thickness was controlled and up-scaled by the number of deposition cycles. The $\mathrm{CsPbBr}_{3}$ film had excellent carrier transport properties comparable to single crystals, such as the mobility of $13 \mathrm{~cm}^{2} \mathrm{~V}^{-1}$ $\mathrm{s}^{-1}$. Therefore, the application of $\mathrm{CsPbBr}_{3}$ films to FPDs will be proceeded using mist deposition method.

\section{Acknowledgments}

This work was supported by Hamamatsu Photonics K. K. and JSPS KAKENHI (Grant No. 17K18988, 18K18943).

\section{References}

1) M.J. Yaffe and J.A. Rowlands, Phys. Med. Biol. 42, 1 (1997).

2) M. Choquette, H. Rougeot, J. Martin, L. Laperriere, Z. Shukri, and B. Polischuk, Proc. SPIE 3977, 128 (2000).

3) G. Belev and S.O. Kasap, J. Non. Cryst. Solids 345-346, 484 (2004).

4) A. Kojima, K. Teshima, Y. Shirai, and T. Miyasaka, J. Am. Chem. Soc. 131, 6050 (2009).

5) A. Wakamiya, M. Endo, T. Sasamori, N. Tokitoh, Y. Ogomi, S. Hayase, and Y. Murata, Chem. Lett. 43, 711 (2014).

6) K. Tanaka, T. Takahashi, T. Ban, T. Kondo, K. Uchida, and N. Miura, Solid State Commun. 127, 619 (2003).

7) M. Kulbak, D. Cahen, and G. Hodes, J. Phys. Chem. Lett. 6, 2452 (2015).

8) Y.C. Kim, K.H. Kim, D.-Y. Son, D.-N. Jeong, J.-Y. Seo, Y.S. Choi, I.T. Han, S.Y. Lee, and N.G. Park, Nature 550, 87 (2017).

9) W. Wei, Y. Zhang, Q. Xu, H. Wei, Y. Fang, Q. Wang, Y. Deng, T. Li, A. Gruverman, L. Cao, and J. Huang, Nat. Photonics 11, 315 (2017).

10) H. Wei, Y. Fang, P. Mulligan, W. Chuirazzi, H.-H. Fang, C. Wang, B.R. Ecker, Y. Gao, M.A. Loi, L. Cao, and J. Huang, Nat. Photonics 10, 333 (2016).

11) H. Wei and J. Huang, Nat. Commun. 10, 1066 (2019).

12) C.C. Stoumpos, C.D. Malliakas, J.A. Peters, Z. Liu, M. Sebastian, J. Im, T.C. Chasapis, A.C. Wibowo, D.Y. Chung, A.J. Freeman, B.W. Wessels, and M.G. Kanatzidis, Cryst. Growth Des. 13, 2722 (2013).

13) D.N. Dirin, I. Cherniukh, S. Yakunin, Y. Shynkarenko, and M. V Kovalenko, Chem. Mater. 28, 8470 (2016).

14) S. Del Sordo, L. Abbene, E. Caroli, A.M. Mancini, A. Zappettini, and P. Ubertini, Sensors 9, 3491 (2009).

15) Z. Yang, M. Wang, J. Li, J. Dou, H. Qiu, and J. Shao, ACS Appl. Mater. Interfaces 10, 26387 (2018).

16) J. Duan, Y. Zhao, X. Yang, Y. Wang, B. He, and Q. Tang, Adv. Energy Mater. 8, 1802346 
(2018).

17) C. Li, C. Han, Y. Zhang, Z. Zang, M. Wang, X. Tang, and J. Du, Sol. Energy Mater. Sol. Cells 172, 341 (2017).

18) K.C. Tang, P. You, and F. Yan, Sol. RRL 2, 1800075 (2018).

19) J. Liang, C. Wang, Y. Wang, Z. Xu, Z. Lu, Y. Ma, H. Zhu, Y. Hu, C. Xiao, X. Yi, G. Zhu, H.

Lv, L. Ma, T. Chen, Z. Tie, Z. Jin, and J. Liu, J. Am. Chem. Soc. 138, 15829 (2016).

20) J.B. Hoffman, G. Zaiats, I. Wappes, and P. V Kamat, Chem. Mater. 29, 9767 (2017).

21) J. Lei, F. Gao, H. Wang, J. Li, J. Jiang, X. Wu, R. Gao, Z. Yang, and S. (Frank) Liu, Sol.

Energy Mater. Sol. Cells 187, 1 (2018).

22) T. Burwig, W. Fränzel, and P. Pistor, J. Phys. Chem. Lett. 9, 4808 (2018).

23) J.B. Hoffman, A.L. Schleper, and P. V Kamat, J. Am. Chem. Soc. 138, 8603 (2016).

24) J. Li, X. Shan, S.G.R. Bade, T. Geske, Q. Jiang, X. Yang, and Z. Yu, J. Phys. Chem. Lett. 7, 4059 (2016).

25) N. Yantara, S. Bhaumik, F. Yan, D. Sabba, H.A. Dewi, N. Mathews, P.P. Boix, H.V. Demir, and S. Mhaisalkar, J. Phys. Chem. Lett 6, 4360 (2015).

26) D.S. Bhachu, D.O. Scanlon, E.J. Saban, H. Bronstein, I.P. Parkin, C.J. Carmalt, and R.G.

Palgrave, J. Mater. Chem. A 3, 9071 (2015).

27) T. Ikenoue, H. Nishinaka, and S. Fujita, Thin Solid Films 520, 1978 (2012).

28) Y. Kamada, T. Kawaharamura, H. Nishinaka, and S. Fujita, Jpn. J. Appl. Phys. 45, L857

(2006).

29) J. Piao, S. Katori, T. Ikenoue, and S. Fujita, Jpn. J. Appl. Phys. 50, 020204 (2011).

30) T. Ikenoue, S. Sakamoto, and Y. Inui, Phys. Status Solidi 11, 1237 (2014).

31) T. Ikenoue, S. Sakamoto, and Y. Inui, Jpn. J. Appl. Phys. 53, 05FF06 (2014).

32) J. Piao, S. Katori, T. Ikenoue, and S. Fujita, Phys. Status Solidi 209, 1298 (2012).

33) T. Ikenoue, N. Kameyama, and S. Fujita, Phys. Status Solidi 8, 613 (2011).

34) H. Nishinaka and M. Yoshimoto, Jpn. J. Appl. Phys. 55, 100308 (2016).

35) P. Zhang, G. Zhang, L. Liu, D. Ju, L. Zhang, K. Cheng, and X. Tao, J. Phys. Chem. Lett. 9, 5040 (2018).

36) Y. He, L. Matei, H.J. Jung, K.M. McCall, M. Chen, C.C. Stoumpos, Z. Liu, J.A. Peters, D.Y. Chung, B.W. Wessels, M.R. Wasielewski, V.P. Dravid, A. Burger, and M.G. Kanatzidis, Nat.

Commun. 9, 1609 (2018).

37) R.H. Bube, J. Appl. Phys. 33, 1733 (1962).

38) M.I. Saidaminov, M.A. Haque, J. Almutlaq, S. Sarmah, X.-H. Miao, R. Begum, A.A.

Zhumekenov, I. Dursun, N. Cho, B. Murali, O.F. Mohammed, T. Wu, and O.M. Bakr, Adv. Opt. 
Mater. 5, 1600704 (2017).

39) H. Zhang, X. Liu, J. Dong, H. Yu, C. Zhou, B. Zhang, Y. Xu, and W. Jie, Cryst. Growth Des. 17, 6426 (2017).

40) J. Zeng, X. Li, Y. Wu, D. Yang, Z. Sun, Z. Song, H. Wang, and H. Zeng, Adv. Funct. Mater. 28, 1804394 (2018).

41) J. Feng, X. Yan, Y. Liu, H. Gao, Y. Wu, B. Su, and L. Jiang, Adv. Mater. 29, 1605993 (2017).

42) W. Nie, H. Tsai, R. Asadpour, J.-C. Blancon, A.J. Neukirch, G. Gupta, J.J. Crochet, M.

Chhowalla, S. Tretiak, M.A. Alam, H.-L. Wang, and A.D. Mohite, Science (80-. ). 347, 522 (2015).

43) J. Song, Q. Cui, J. Li, J. Xu, Y. Wang, L. Xu, J. Xue, Y. Dong, T. Tian, H. Sun, and H. Zeng, Adv. Opt. Mater. 5, 1700157 (2017).

\section{Figure Captions}

Fig. 1. Schematic image of the mist deposition method.

Fig. 2. (a)-(d) Photographs and (e)-(h) cross-sectional SEM images of the $\mathrm{CsPbBr}_{3}$ films formed at (a, e) 130, (b, f) 150, (c, g) 170, and (d, h) $190^{\circ} \mathrm{C}$. Scale bars are $5 \mu \mathrm{m}$. (i) XRD patterns of films formed at $130-190{ }^{\circ} \mathrm{C}$, (j) Tauc plot for the film formed at $150{ }^{\circ} \mathrm{C}$.

Fig. 3. (a) Relation between the film thickness and the number of deposition cycles, $N$, (b)(d) cross-sectional SEM images of films formed at deposition cycles of (b) 10, (c) 30, and (d) 50 . Scale bars are $10 \mu \mathrm{m}$.

Fig. 4. Dark current density-voltage characteristics of a $\mathrm{CsPbBr} 3$ film. 
Table I Carrier transport properties and size comparisons of $\mathrm{CsPbBr}_{3}$ from previous reports.

\begin{tabular}{ccccccc}
\hline Method & Structure & Size & $R[\mathrm{G} \Omega \mathrm{cm}]$ & $\begin{array}{c}n_{\text {trap }}\left[\mathrm{cm}^{-3}\right] \\
\text { electron } / \text { hole }\end{array}$ & $\begin{array}{c}\mu\left[\mathrm{cm}^{2} \mathrm{~V}^{-1} \mathrm{~s}^{-1}\right] \\
\text { electron } / \text { hole }\end{array}$ & Ref. \\
\hline Bridgman & SC & $\phi 24 \mathrm{~mm} \times 90 \mathrm{~mm}$ & - & $1.08 \times 10^{9} /-$ & $11.61 /-$ & $35)$ \\
Bridgman & SC & $\phi 25 \mathrm{~mm} \times 70 \mathrm{~mm}$ & - & $-/ 1.2 \times 10^{9}$ & $2290 / 2060$ & $43)$ \\
ITC & SC & $3 \mathrm{~mm} \times 2 \mathrm{~mm} \times 1 \mathrm{~mm}$ & 0.1 & $1.1 \times 10^{10} / 4.2 \times 10^{10}$ & $52 / 11$ & $38)$ \\
AVC* & SC & $42 \mathrm{~mm} \times 5 \mathrm{~mm} \times 3 \mathrm{~mm}$ & 2.1 & - & $-/ 143$ & $39)$ \\
Spin-coating & thin film & - & - & $1.40 \times 10^{16}$ & - & $41)$ \\
Spin-coating & porous film & $40 \mathrm{~mm} \times 40 \mathrm{~mm} \times<1 \mu \mathrm{m}$ & - & $3.07 \times 10^{12}$ & 9.27 & $40)$ \\
Mist deposition & thick film & $25 \mathrm{~mm} \times 6 \mathrm{~mm} \times 28 \mu \mathrm{m}$ & 1.4 & $1.3 \times 10^{12}$ & 13 & This work \\
\hline
\end{tabular}

*AVC; Anti-solvent vapor-assisted crystallization 


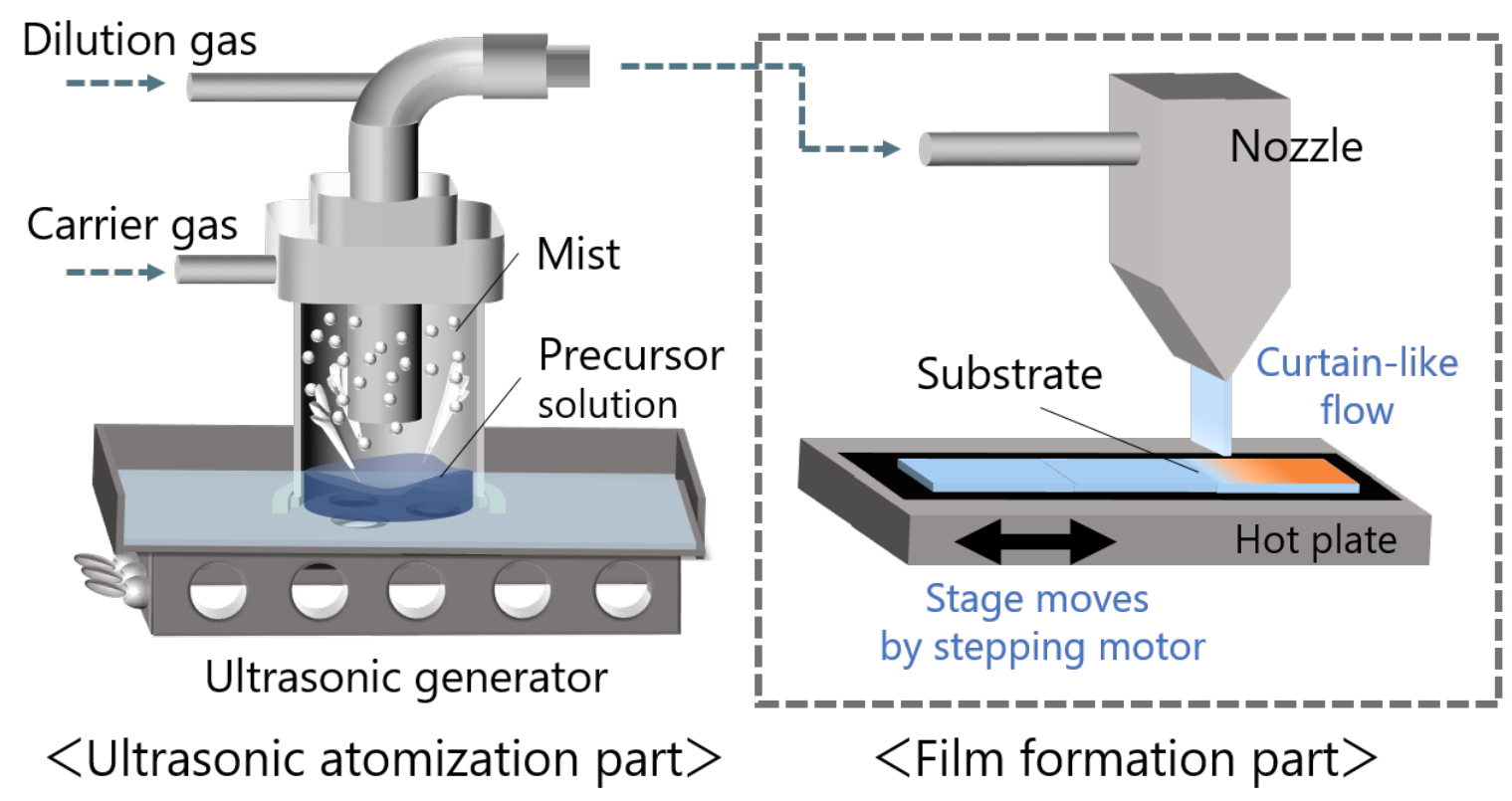

Fig. 1. 

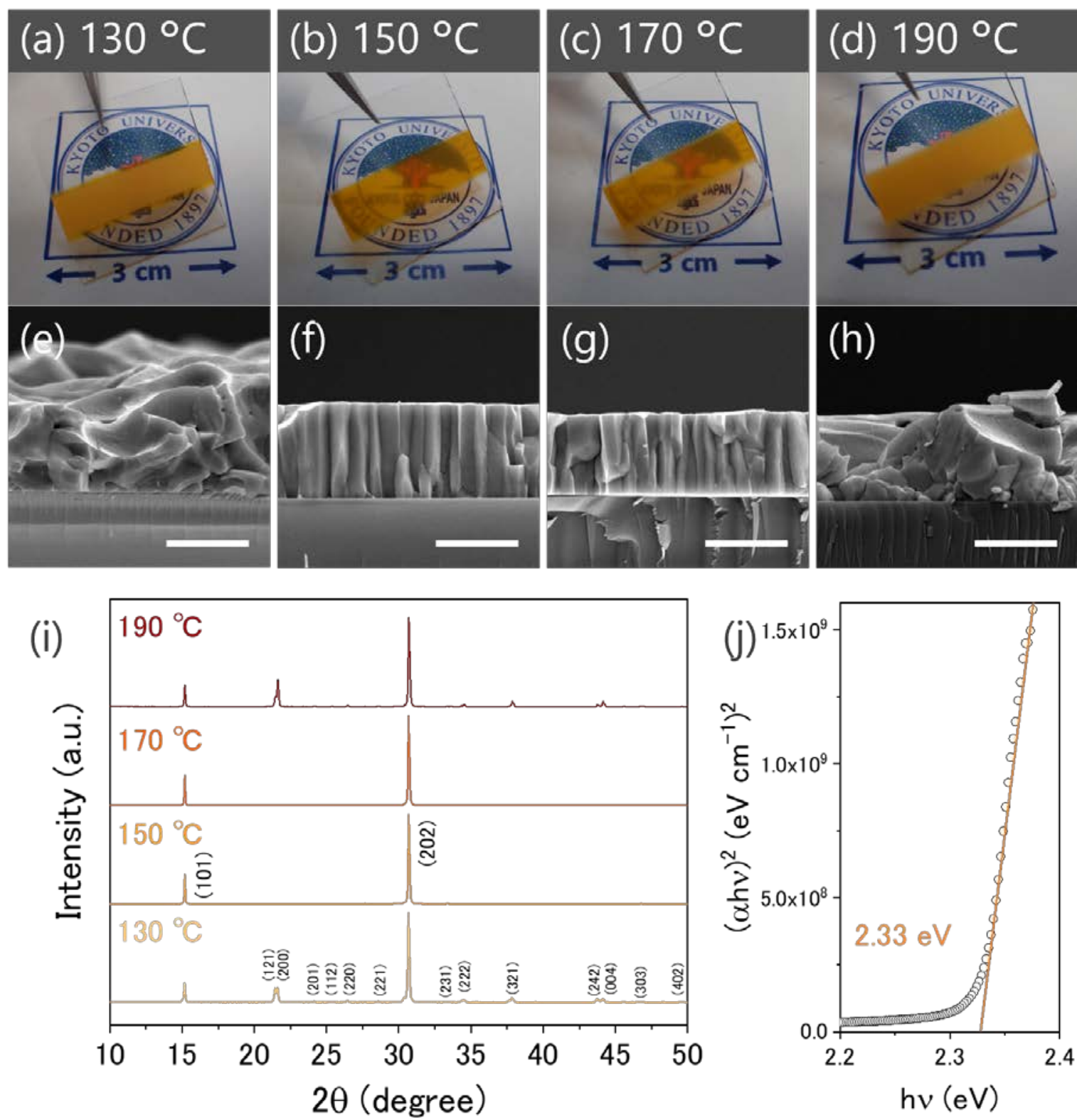

Fig. 2. 
(a)
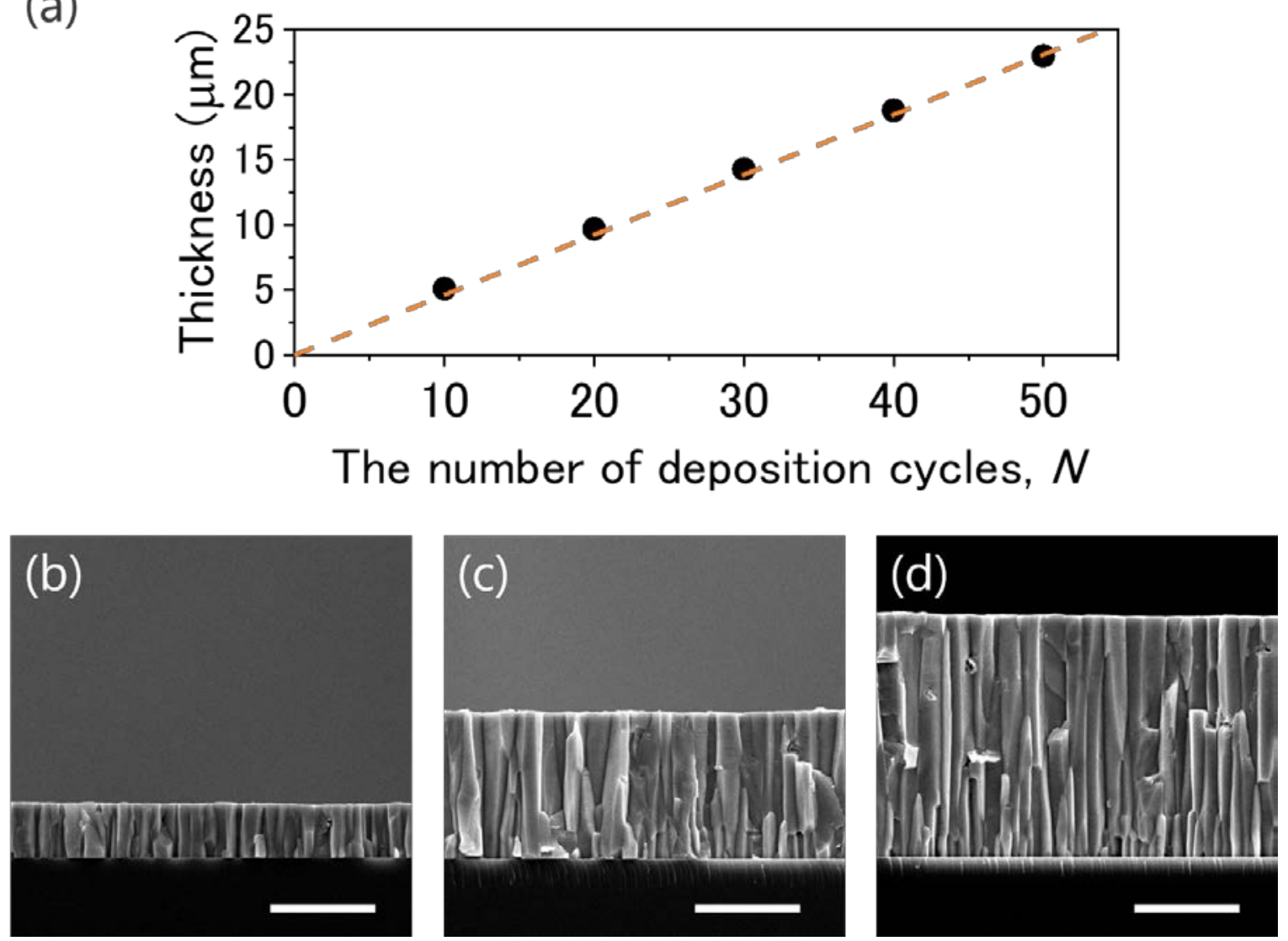

Fig. 3. 


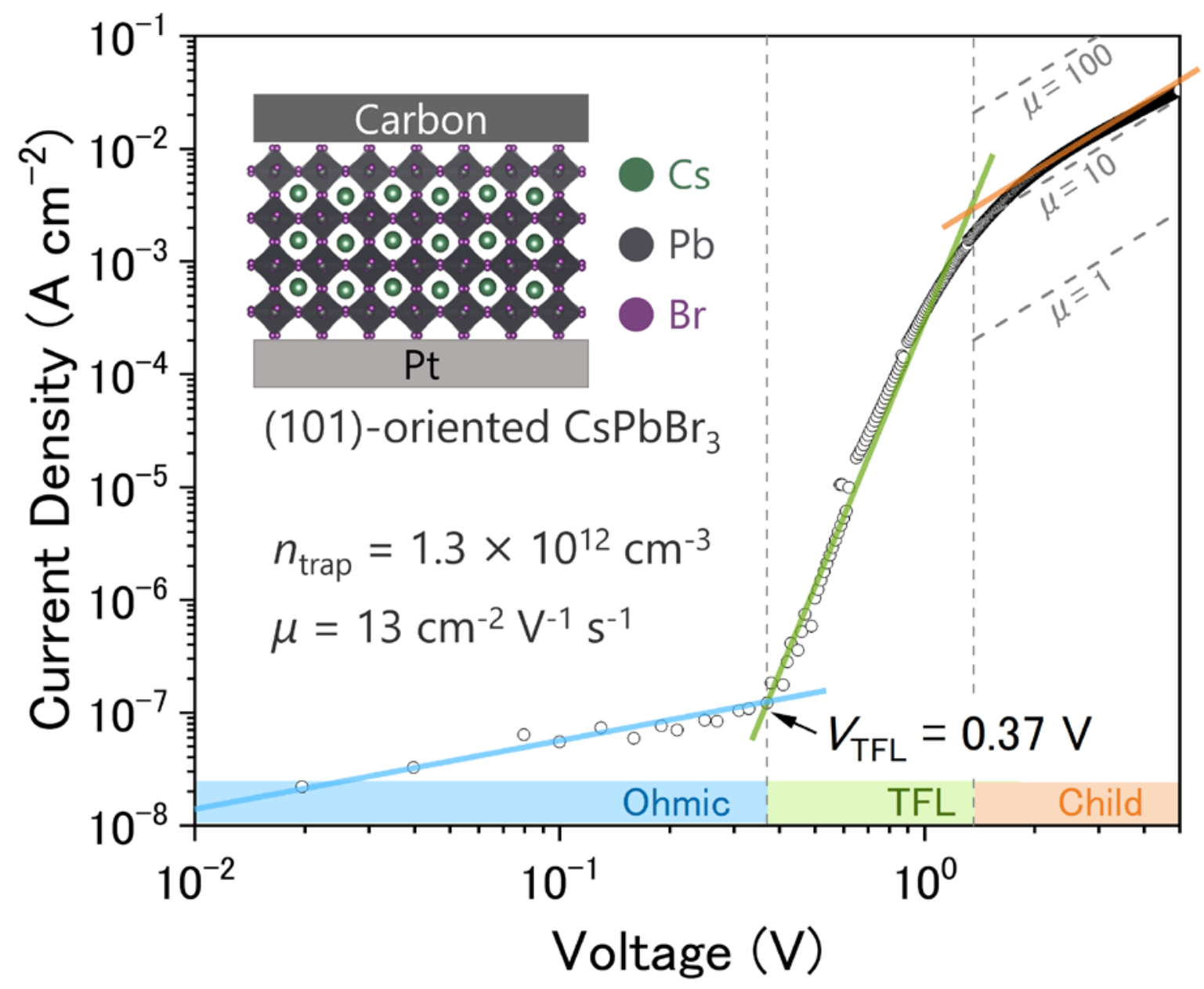

Fig. 4. 